\title{
Association between Paraoxonase-I p.Q192R Polymorphism and Coronary Artery Disease susceptibility in the Colombian Population
}

\author{
David Corredor-Orlandelli (D) ${ }^{1, *}$ \\ Santiago Sambracos-Parrado I,* \\ Santiago Mantilla-García ' \\ Josué Tovar-Tirado' \\ Valentina Vega-Ramírez' \\ Santiago David Mendoza-Ayús' \\ Laura Catalina Peña' \\ María Fernanda Leal' \\ Juliana Rodríguez-Carrillo' \\ Juanita León-Torres' \\ Juan Mauricio Pardo-Oviedo (iD ${ }^{2}$ \\ Katherine Parra Abaunza ${ }^{3}$ \\ Nora Contreras Contreras Bravo (iD) \\ Oscar Ortega-Recalde iD ' \\ Dora Janeth Fonseca Mendoza (D) \\ 'Center for Research in Genetics and \\ Genomics - CIGGUR, GENIUROS \\ Research Group, School of Medicine and \\ Health Sciences, Universidad Del Rosario, \\ Bogotá, Colombia; ${ }^{2}$ School of Medicine and \\ Health Sciences, Universidad del Rosario, \\ Bogotá, Colombia; ${ }^{3}$ Hospital Universitario \\ Mayor - Méderi, Universidad del Rosario, \\ Bogotá, Colombia
}

*These authors contributed equally to this work

Correspondence: Dora Janeth Fonseca Mendoza

Center for Research in Genetics and Genomics (CIGGUR), GENIUROS

Research Group, School of Medicine and Health Sciences, Universidad del Rosario, Cra 24 \# 63C69, Bogotá, I I 1 II I, Colombia $\mathrm{Tel} / \mathrm{Fax}+57$ I2920200

Email dora.fonseca@urosario.edu.co
Background: Paraoxonase-1 (PON1), a glycoprotein associated with serum high-density lipoprotein (HDL), has a central role in metabolizing lipid peroxides, exhibiting antiatherogenic properties. The polymorphism p.Q192R has been previously associated with coronary artery disease (CAD) susceptibility and clopidogrel response.

Purpose: We aimed at investigating the association of PON1 p.Q192R with CAD and clopidogrel response in Colombian population.

Patients and Methods: The study was conducted among 163 patients diagnosed with CAD and treated with clopidogrel. The allele frequencies for the PON1 192Q and 192R alleles were determined in cases and Latin-American controls obtained from the public database gnomAD ( $n=17,711$ ). Response to clopidogrel was determined by assessing the platelet function using the INNOVANCE PFA-200 System. We determined the association between PON1 p.Q192R polymorphism, increased susceptibility to $\mathrm{CAD}$ and high on-treatment platelet reactivity (HPR) by using odds ratio (OR) and 95\% confidence interval (CI) on four genetic models.

Results: The allele frequencies for the PON1 192Q and 192R alleles were 0.60 and 0.40, respectively. The allele distribution was found to be statistically different from the control group and other ethnic groups. The allele 192R was positively associated with decreased susceptibility to CAD under a dominant model (OR, 0.58; 95\% CI, 0.42-0.8; P < 0.01). We found no association between the polymorphism and HPR.

Conclusion: We propose that PON1 p.Q192R is a potentially useful marker for CAD susceptibility in the Colombian population and lacks association with HPR under clopidogrel treatment. Keywords: PON1, genetic risk, cardiovascular disease susceptibility, platelet reactivity, clopidogrel

\section{Introduction}

Coronary artery disease (CAD) is the most prevalent cardiovascular disease and the leading cause of mortality globally, accounting for $16 \%$ of deaths worldwide. ${ }^{1}$ In 2019 , 8.9 million deaths were caused by this disease, representing a major burden on healthcare systems, especially in developing countries. ${ }^{2}$ CAD is almost always due to atheromatous vessel narrowing and subsequent impaired blood flow to the heart. Blood flow occlusion results in both acute and chronic conditions, such as stable angina, acute coronary syndrome (ACS) and chronic ischemic heart disease. ${ }^{3}$ Nongenetic risk factors for atherosclerosis have been thoroughly described and are highly prevalent in the Latin-American population. ${ }^{4}$ Importantly, the complex interaction between these factors and genetic factors, including single-nucleotide polymorphisms 
(SNP), has taken a central role in understanding the pathophysiology of this disease and the extensive variability susceptibility observed in populations. ${ }^{5,6}$ Among the genetic factors, paraoxonase-1 (PON1) is one of the most studied risk factors. PON1 is a glycoprotein associated with serum high-density lipoprotein (HDL) and has a central role in metabolizing lipid peroxides, exhibiting antiatherogenic properties. ${ }^{7}$ Previous studies on animal models have shown that transgenic PON1 knockout mice developed increased lipid oxidation and atherosclerosis. ${ }^{8}$ Conversely, overexpression of PON1 showed opposite results. ${ }^{9}$ Furthermore, metaanalysis of clinical studies suggests a link between low levels of PON1 in serum and increased risk of CAD.$^{10}$ The PON1 $p$. Q192R missense variant (c.575A $>\mathrm{G}$, rs662) is the most extensively characterized PON1 SNP and has been associated with CAD susceptibility in numerous studies. ${ }^{11-19}$ Intriguingly, other studies could not replicate this association, whereby the role of PON1 Q192R in CAD remains controversial. ${ }^{20-22}$

PON1 is considered a key factor for the bioactivation and clinical activity of clopidogrel, an ADP P2Y12 receptor antagonist recommended as a first-line treatment for ACS. ${ }^{23,24}$ Likewise, the PON1 Q192R variant has been associated with lower PON1 levels in serum, lower serum levels of clopidogrel active metabolites and higher platelet reactivity. ${ }^{25}$ Notably, extensive interindividual variability in the platelet response to clopidogrel has been observed. ${ }^{26}$ Previous studies have shown that approximately $83 \%$ of clopidogrel response variance can be attributed to genetic factors and between $4 \%$ and $30 \%$ patients develop therapeutic failure. ${ }^{27,28}$ Noteworthy, most of the studies conducted to prove the associations between the PON Q192R variant, CAD risk and response to clopidogrel have been performed on non-Latin-American populations. The lack of studies on this population limits the implementation of pharmacogenetic interventions and genetic risk estimation, therefore, new studies are required to clarify these relationships.

In this study, we performed a retrospective case-control analysis to identify the correlation between the PON1 Q192R variant, the risk of CAD and platelet response to clopidogrel in a cohort of Colombian patients with ACS. Patients were recruited from a previous study where polymorphisms on CYP2C19 and clopidogrel responses were assessed. ${ }^{29}$ The present study identified a positive association between the PON1 Q192R variant and decreased susceptibility to CAD. To our knowledge, this is the first case-control association study to assess the association between PON1 Q192R and $\mathrm{CAD}$ susceptibility in the Colombian population. These results provide an insight into the genetic factors involved in CAD pathophysiology in the Colombian population.

\section{Patients and Methods}

\section{Sampling and Data Collection}

The cohort of the present study consisted of 163 patients being treated for ACS at the Hospital Universitario Mayor - Méderi, Colombia. The study included patients older than 18 years that fulfilled the diagnostic criteria of ACS (including unstable angina and myocardial infarction with and without ST elevation) established by the Colombian ACS practice guidelines. ${ }^{30}$ All patients received a $300 \mathrm{mg}$ clopidogrel loading dose followed by $75 \mathrm{mg}$ daily for at least seven days. Individuals with abnormal hematocrit levels $(<25 \%$ and $>52 \%)$, platelet count $<100,000$, creatinine $<1.5 \mathrm{mg} / \mathrm{dL}$ and/or clinical signs of impaired liver and/or platelet function were excluded from the study. Eligible patients were invited to participate in the study, and after detailed explanation, informed consent was obtained prior to sample and data collection. The control group was constituted by data from 17,711 Latino/Admixed individuals obtained from the gnomAD database v2.1.1. ${ }^{31}$ All experimental procedures in this study were approved by the Ethics Committee of Universidad del Rosario (Approval DVO005 990-CV1018; Institutional review board reference IV-FPC015 and ABN062) and followed the Helsinki Declaration Principles. The consent was obtained by the study participants prior to the study commencement.

\section{Genotyping of the PONI C. 575 A>G Polymorphism}

Genomic DNA was obtained from peripheral blood leukocytes using the Quick-DNATM MiniPrep Plus Kit (Zymo research). The blood samples were collected in EDTA tubes, $5 \mathrm{~mL}$ for patient, and processed within 24 hours after collection. Genomic DNA was quantified using a nanodrop spectrophotometer. The samples were aliquoted and stored at $-4^{\circ} \mathrm{C}$ until analysis. Genomic regions flanking the PON1 Q192R (c.575 $A>G$ ) variant located in exon 6 were amplified using polymerase chain reaction (PCR). The primers amplification sequences were F: 5'-TGT CTA AGG ATT GTA TCG GCA GG-3' and R: 5'-CTT CAT CAC AGT TCC CCC TCT T-3'. The PCR conditions were as follows: initial denaturation at $95^{\circ} \mathrm{C}$ for 10 minutes; 30 cycles consisting of $95^{\circ} \mathrm{C}$ for $40 \mathrm{~s}, 60^{\circ}$ $\mathrm{C}$ for $40 \mathrm{~s}$, and $72^{\circ} \mathrm{C}$ for $40 \mathrm{~s}$; and final extension at $72^{\circ} \mathrm{C}$ for $10 \mathrm{~min}$. The PCR products were visualized on agarose gels (1.5\%) by ethidium bromide staining. The PCR product length was 631 bp (Figure 1A). PCR amplified products were 

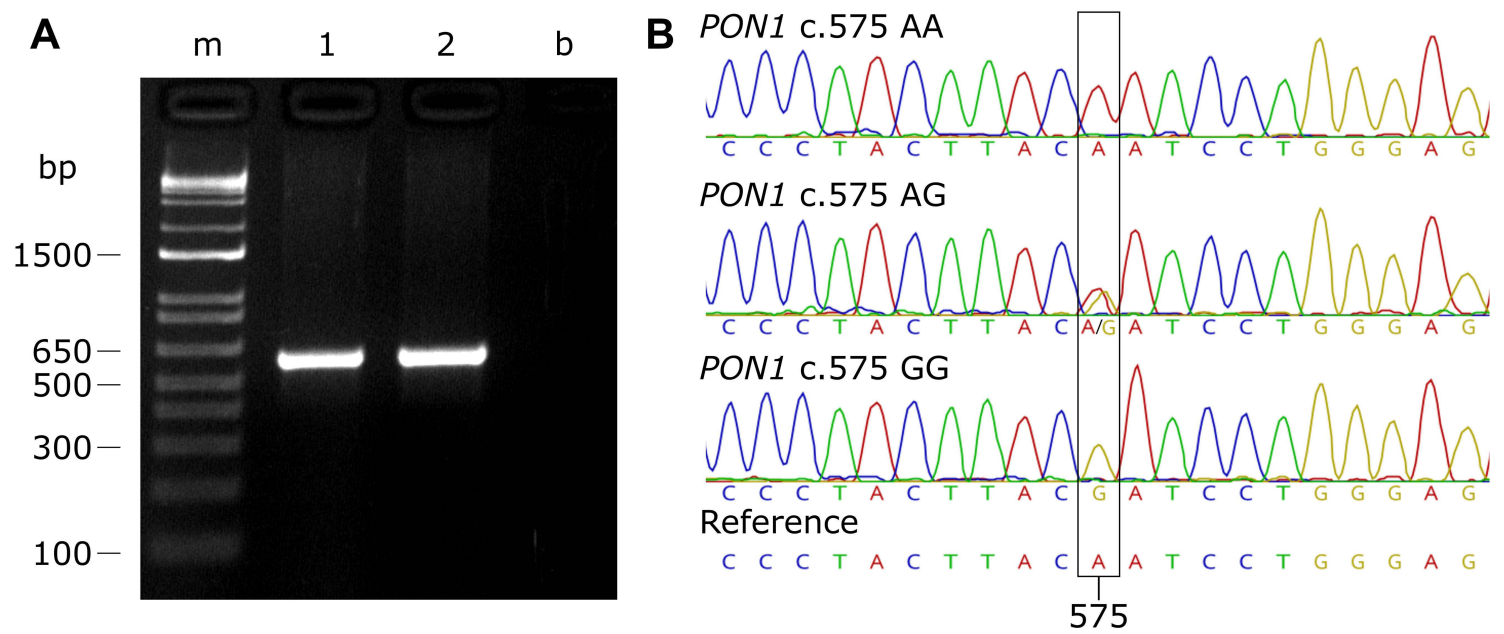

Figure I PONI c.575A $>$ G genotypification. (A) Agarose gel electrophoresis of amplicon products generated by PCR. (B) Sanger sequencing chromatogram showing the $P O N /$ c.575A $>G$ genotypes.

Abbreviations: bp, base pairs, m, molecular ladder; b, blank (negative control)

sequenced through Sanger method. The reference sequence was obtained from Ensembl (ENSG00000005421). Sequences were analyzed with FinchTV v1.5.0 (Geospiza Inc.) and aligned with the reference sequence using Clustal W v2.1 for comparison (http://www.clustal.org/) (Figure 1B).

\section{Platelet Function Analysis}

Platelet function was determined using the INNOVANCE Platelet Function Analyzer (PFA)-200 P2Y system (Siemens Healthcare) following manufacturer's instructions. Briefly, this assay simulates platelet adhesion and in vitro aggregation using a membrane covered with $20 \mathrm{ug}$ of adenosine diphosphate (ADP), $5 \mathrm{ng}$ of prostaglandin E1 (PGE1) and $125 \mathrm{ug}$ of calcium. Blood samples were collected at least 24 hours after the loading dose of clopidogrel, with a maximum of 7 days, stored in citrated tubes and processed before 4 hours post-collection. High ontreatment platelet reactivity (HPR) was defined as a closure time of less than 106 seconds as suggested by the manufacturer.

\section{Statistical Analyses}

Allelic and genotypic frequencies for PON1 Q192R polymorphisms were calculated using the SNPStats web tool (https://www.snpstats.net/). Hardy-Weinberg equilibrium (HWE) was estimated using a $\chi^{2}$ goodness-of-fit test. The $\chi 2$ test was used to compare allele frequencies between the groups. The best-fitting genetic model was chosen according to Akaike's interpretation criterion (AIC) using the SNPassoc v2.02 R package. ${ }^{32}$ According to the results of the INNOVANCE PFA-200 P2Y assay, patients were classified in either an HPR or a non-HPR group. Statistical differences between the two groups were calculated using the $\chi 2$ test. A Kruskal-Wallis test was performed to evaluate the differences between genotypic groups according to the PFA-200 P2Y assay exact values. Allelic and genotypic frequencies were obtained from numerous studies for comparisons. ${ }^{11-22,33-41}$ The $P$ value for significance was set at $<0.05$. Analyses were conducted using R v4.0.3 (R Core Team, 2014) or SPSS v26 208 software (IBM Analytics).

\section{Results}

\section{Baseline Characteristics of the Study Population}

Demographic and clinical characteristics for the study cohort are shown in Table 1. The median age at the event was 67 years (range 45-87 years) and 63.2\% patients were male. The most prevalent type of ACS in this group was the non-ST segment elevation myocardial infarction (63.8\%). Among the patients included in our cohort $32.5 \%$ had previous history of myocardial infarction, and nearly $30 \%$ had at least one cardiovascular comorbidity (eg, dyslipidemia, diabetes mellitus, and obesity). The cohort for this study was derived from a previous study described by Angulo et al. ${ }^{29}$ The control group consisted of 17,711 Latino/Admixed general population obtained from the gnomAD database; 7371 individuals were reported as female and 10,340 as male. 
Table I Demographic and Clinical Characteristics of the Cohort

\begin{tabular}{|c|c|c|c|}
\hline Variable & Characteristic & Number $(n=163)$ & Percentage (\%) \\
\hline \multirow[t]{2}{*}{ Sex } & Female & 60 & 36.8 \\
\hline & Male & 103 & 63.2 \\
\hline \multirow[t]{3}{*}{ Age (years) } & $30-49$ & 9 & 5.5 \\
\hline & $50-70$ & 88 & 54 \\
\hline & $>70$ & 66 & 40.5 \\
\hline \multirow[t]{3}{*}{ ACS type } & STEMI & 35 & 21.5 \\
\hline & NSTEMI & 104 & 63.8 \\
\hline & Unstable angina & 24 & 14.7 \\
\hline \multirow[t]{4}{*}{ Body Mass Index } & Underweight $(<18.5)$ & 2 & 1.2 \\
\hline & Normal (18.5-24.9) & 57 & 35 \\
\hline & Overweight (25-29.9) & 62 & 38 \\
\hline & Obese $(>29.9)$ & 42 & 25.8 \\
\hline \multirow[t]{3}{*}{ Intervention type } & Medical & 43 & 26.4 \\
\hline & $\mathrm{PCl}$ & 84 & 51.5 \\
\hline & CABG & 36 & 22.1 \\
\hline Antecedent of myocardial infarction & Yes & 53 & 32.5 \\
\hline Smoking & Yes & 12 & 7.3 \\
\hline Alcohol consumption & Yes & 5 & 3.1 \\
\hline Stent placement current event & Yes & 71 & 43.6 \\
\hline CAD familiar history & Present & 64 & 39.3 \\
\hline Type 2 Diabetes Mellitus & Present & 45 & 27.6 \\
\hline Hypertension & Yes & 111 & 68.1 \\
\hline Dyslipidemias & Yes & 55 & 33.7 \\
\hline & Missing data & 1 & 0.6 \\
\hline Statin usage & Yes & 143 & 87.7 \\
\hline
\end{tabular}

Abbreviations: ACS, acute coronary syndrome; CABG, coronary artery bypass grafting; CAD, coronary artery disease; NSTEMI, non-ST-segment elevation myocardial infarction; PCl, percutaneous coronary intervention; STEMI, ST-segment elevation myocardial infarction.

\section{PONI Q192R Genotypic and Allelic Frequencies}

A 631 base pairs fragment, containing the PON1 c.575 $\mathrm{A}>\mathrm{G}$ polymorphism, was amplified and sequenced in the case-cohort. Genotypes were determined by interpretation of chromatogram peaks using the FinchTV v1.5 and assigned as homozygous for the wild-type allele AA, heterozygous AG, and homozygous for the polymorphic allele GG (Figure 1). Genotype and allele frequencies for the case and controls are shown in Table 2. AA wild-type genotype was found in $38.0 \%$ of patients, while AG heterozygous and GG homozygous individuals were $44.2 \%$ and $17.8 \%$, respectively. The genotypic distribution for the PON1 gene polymorphism assessed in the case-cohort was in HWE. The minor allele frequency (MAF) for the R192 allele was 0.40 (R allele) compared with 0.49 in the control group $(P<0.05)$.

Allelic frequencies for the Colombian population were compared with those of other studies, including 6 populations of European ancestry, 4 Asian, 4 African, 2 from North America, and 6 from Latin-America (Table 3). Interestingly, allelic frequencies were significantly different from 15 populations (68\%). East Asian populations are reported to have a higher frequency of the Q192R variant, while allele frequencies for Caucasian populations are lower $(\mathrm{P}<0.05)$. Regarding other Latin-American populations, the cohort of Colombian patients showed higher allele frequencies than those from Mexico, Peru and 
Table 2 Allelic and Genotypic Frequencies of PONI Q192R in Case and Control Groups

\begin{tabular}{|l|l|l|l|l|l|l|}
\hline $\begin{array}{l}\text { Genotypel } \\
\text { Allele }\end{array}$ & $\begin{array}{l}\text { Cases } \\
(\mathbf{n}=\mathbf{1 6 3})\end{array}$ & $\begin{array}{l}\text { Frequency } \\
\text { (Cases) }\end{array}$ & $\begin{array}{l}\text { HWE } \boldsymbol{P} \text { value } \\
\text { (Cases) }\end{array}$ & $\begin{array}{l}\text { Controls } \\
(\mathbf{n}=17,771)\end{array}$ & $\begin{array}{l}\text { Frequency } \\
\text { (Cases) }\end{array}$ & $\begin{array}{l}\text { HWE } \boldsymbol{P} \text { value } \\
\text { (Controls) }\end{array}$ \\
\hline QQ & 62 & 0.380 & & 4659 & 0.263 & \\
QR & 72 & 0.442 & & 8601 & 0.486 & \\
RR & 29 & 0.178 & 0.31 & 4451 & 0.251 & $<0.01 *$ \\
Q & 196 & 0.601 & & 17,919 & 0.506 & \\
R & 130 & 0.399 & & 17,503 & 0.494 & \\
\hline
\end{tabular}

Note: $* \mathrm{P}$ value $<0.05$.

Abbreviations: HWE, Hardy-Weinberg equilibrium; Q, glutamine; R, arginine.

Puerto Rico. Moreover, allele frequencies were significantly lower than in the Argentinian population. The genotypic frequencies obtained in this study were similar to those observed in Brazil.

\section{PONI Q192R Has a Positive Association with CAD Susceptibility but Not with Platelet Reactivity}

Association analysis was conducted under various genetic models including codominant (QQ; QR and RR), dominant (QQ vs QR-RR) and recessive (QQ-QR vs RR). All of them showed significant differences between cases and controls for the PON1 Q192R polymorphism (Table 4). According to the AIC, the dominant model was supported the best, whereas the least supported was the recessive model. Results showed that individuals carrying both a QR genotype and an RR genotype had a lower risk of CAD (dominant model: OR, 0.58; 95\% CI, 0.42-0.8; P < 0.01) (Table 4).

The CT value was assessed by the INNOVANCE PFA200 P2Y system (Siemens Healthcare). According to PFA200 P2Y assay results, patients were assigned to the HPR (CT $<106$ seconds) and non-HPR groups $(\mathrm{CT}>106$ seconds). As shown in Table 5, 56 patients were HPR and 107 were non-HPR. We did not observe an association between the PON1 genotype and the HPR group under any of the genetic models tested, the PON1 genotype or the PFA mean range values.

\section{Discussion}

HDL particles play a central role in protecting both lipids and proteins against free radical-induced oxidation and plaque formation, playing a central role in the genesis and development of CAD. ${ }^{7}$ Enzymatic components potentially contributing to the antioxidative properties of HDL include PON1, platelet-activating factor acetylhydrolase (PAFAH) and lecithin-cholesterol acyltransferase (LCAT) ${ }^{42}$
Numerous studies have shown that altered levels of PON1 lead to atherosclerosis and cardiac events, highlighting the positive association between the PON1 Q192R variant and both CAD susceptibility and 10-year survival..$^{8-19,33}$ To determine this relationship in a Latin-American population, we genotyped PON1 p.Q192R in a cohort of patients with $\mathrm{CAD}$. Our results illustrate a positive association between this variant and susceptibility to CAD in the Colombian population, finding that the 192R allele confers a lower risk of developing CAD under a dominant genetic model (OR, $0.58 ; 95 \%$ CI, 0.42-0.8; $P<0.01)$.

The functional and clinical relevance of PON1 in CAD development has been documented in several models. In mice, for example, PON1 overexpression demonstrated protection against atherosclerosis, whereas Pon1-deficient animals showed an increased risk of this phenotype. ${ }^{9,43}$ PON1 enzymatic activity is affected by several environmental and genetic factors, and among these, the polymorphism PON1 p.Q192R has been characterized as a major determinant. ${ }^{44}$ The 192Q PON1 alloenzyme showed a 3-fold lower affinity to HDL particles and, therefore, lower molecular stability, lipolactonase activity and modulatory effect on macrophage cholesterol efflux. ${ }^{45} \mathrm{~A}$ recent systematic review and meta-analysis conducted by Hernandez-Diaz et al, including 64 case-control studies, 19,715 cases and 33,397 controls, mainly Asian, European, and African populations, conclude that the 192R allele significantly decreased the risk of myocardial infarction and coronary artery disease in certain populations. ${ }^{44}$ Despite these findings, genotype analyses of PON1 as a predictor of vascular disorders have reported mixed results. For example, studies conducted in Turkey, India and Spain showed no significant differences in the distribution of PON1 Q192R polymorphism and the phenotypes assessed. ${ }^{46-48}$ Other studies have linked allele 192R and genotype RR as CAD risk factors. ${ }^{12,49}$ These contrasting results may be due to a) heterogeneity across 


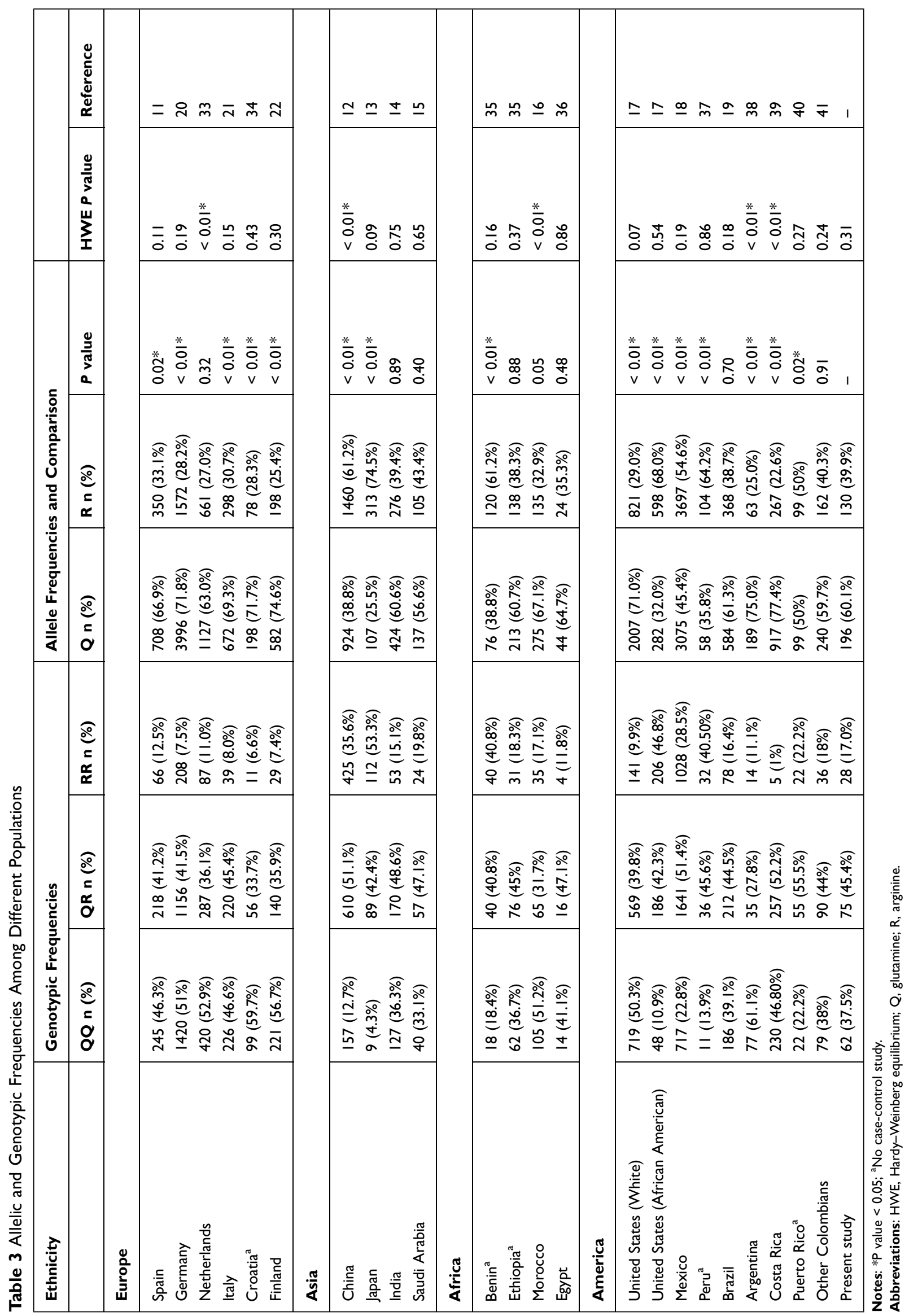


Table 4 Association Between PONI QI92R Polymorphism and Coronary Artery Disease

\begin{tabular}{|c|c|c|c|c|c|c|c|c|c|}
\hline Model & Control & $\%$ & Case & $\%$ & OR & Lower & Upper & $P$ value & AIC \\
\hline \multicolumn{10}{|c|}{ Codominant } \\
\hline QQ & 4659 & 26.3 & 62 & 38 & I & - & - & $<0.01^{*}$ & 1850 \\
\hline QR & 8601 & 48.6 & 72 & 44.2 & 0.63 & 0.45 & 0.89 & & \\
\hline RR & 4451 & 25.1 & 29 & 17.8 & 0.49 & 0.31 & 0.76 & & \\
\hline \multicolumn{10}{|c|}{ Dominant } \\
\hline QQ & 4659 & 26.3 & 62 & 38 & I & - & - & $<0.01^{*}$ & 1849 \\
\hline$Q R+R R$ & 13052 & 73.7 & 101 & 62 & 0.58 & 0.42 & 0.8 & & \\
\hline \multicolumn{10}{|l|}{ Recessive } \\
\hline $\mathrm{QQ}+\mathrm{QR}$ & 13260 & 74.9 & 134 & 82.2 & I & - & - & $<0.01^{*}$ & 1855 \\
\hline RR & 4451 & 25.1 & 29 & 17.8 & 0.84 & 0.43 & 0.96 & & \\
\hline \multicolumn{10}{|c|}{ Over-dominant } \\
\hline $\mathrm{QQ+RR}$ & 9110 & 51.4 & 91 & 55.8 & I & - & - & 0.26 & 1859 \\
\hline QR & 8601 & 48.6 & 72 & 44.2 & 0.61 & 0.61 & 1.14 & & \\
\hline
\end{tabular}

Note: $* \mathrm{P}$ value $<0.05$

Abbreviations: AIC, Akaike's interpretation criterion; OD, Odds ratio; Q, Glutamine; R, Arginine.

the studied populations, b) impact of strong linkage disequilibrium in several ethnic groups, c) incidence of vascular disease, d) presence of promoter SNPs not analyzed in the studies, e) roles of both genetic and environmental influences on PON1 activity and f) gene-gene interactions. ${ }^{50}$

Regarding the implications of the PON1 Q192R polymorphism in the response to clopidogrel assessed by platelet aggregation, our study suggests that the variants assessed do not confer susceptibility to HPR. Bouman et al performed an in vitro study identifying PON1 as a crucial enzyme that converts 2-oxo-clopidogrel into an active thiol metabolite. ${ }^{23}$ Furthermore, they reported that

Table 5 Association Analysis Between Platelet Reactivity and Genotype

\begin{tabular}{|l|l|l|l|l|}
\hline Model & Genotype & $\begin{array}{l}\text { HPR }(\mathbf{n}= \\
\mathbf{5 6})\end{array}$ & $\begin{array}{l}\text { Non-HPR (n } \\
\mathbf{= 1 0 7})\end{array}$ & $\begin{array}{l}\boldsymbol{P} \\
\text { value }\end{array}$ \\
\hline Dominant & QQ & 21 & 41 & 0.96 \\
& QR+RR & 35 & 66 & \\
\hline Codominant & QQ & 21 & 41 & 0.99 \\
& QR & 25 & 48 & \\
& RR & 10 & 18 & 0.96 \\
\hline Recessive & QQ+QR & 46 & 89 & 18 \\
& RR & 10 & 18 & \\
\hline
\end{tabular}

Abbreviations: HPR, high on-treatment platelet reactivity; $Q$, glutamine; $R$, arginine.
PON1 Q192R was a major determinant of clopidogrel efficacy, responsible for about $70 \%$ of the variability in ADP-stimulated platelet aggregation response after clopidogrel treatment. ${ }^{23}$ These observations positioned PON1 as a relevant pharmacogenetic marker and proposed that homozygous individuals for the PON1 192Q allele had a higher risk of stent thrombosis compared to those carrying at least 1 PON1 192R allele. The clinical relevance of this finding has generated several studies aiming to replicate this association in different populations. Nevertheless, similar to our results, numerous studies have not found a link between the PON1 Q192R polymorphism and platelet reactivity or clinical outcome. ${ }^{51,52}$ The discrepancy between these results has been attributed to methodological inconsistencies in Bouman's work, discussed at length by Camps et al, who suggested that at least two factors might have influenced the results; a) the measurement of PON1 activity was conducted with plasma containing EDTA, a strong inhibitor of PON1, b) the influence of other proteins in the PON1 enzymatic activity was not assessed in the study. ${ }^{53}$ Murine models have supported these observations. A recent study using PON1-deficient mice, in which platelet reactivity was assessed by PFA100, showed PON1 deficiency does not influence the antiplatelet action of clopidogrel in mice. ${ }^{54}$ These results reinforce the hypothesis that the enzyme is not involved in clopidogrel bioactivation and may explain the lack of 
association between PON1 genotypes and drug response observed in our study.

Allele frequencies for the PON1 Q192R polymorphism were compared to populations of different ethnic backgrounds (Table 3 ) revealing statistically significant differences between our cohort and specific population of the different ancestries (Caucasian, Asian, and some LatinAmerican) $(P<0.05)$. It has been reported that two polymorphisms on PON1, Q192R and L55M, explain a great amount of the interindividual variation (up to 13-fold) observed in this enzyme and, importantly, both are heterogeneously distributed worldwide. ${ }^{55}$ Previous studies in European populations showed higher frequencies for the 192Q allele $(\sim 0.7)$, while for East Asian populations, the $192 \mathrm{R}$ allele is more common $(\sim 0.7)$. Adding to the wide genotypic variation observed worldwide, our results reveal that the PON1 192R allele is more frequent in Colombian population $(\sim 0.4)$ than in Caucasian populations, but less frequent than in East Asians. Colombia has a high degree of genetic admixture and amongst Latin American countries has the highest interpopulation variability. ${ }^{56}$ These findings have potential clinical implications, for example, given the positive association between the 192Q allele and vascular disease, this polymorphism may be useful as a biomarker for cardiovascular risk in specific populations.

Interestingly, the allele frequencies for 192R found in our study were similar to those reported in African populations ( 0.4). A previous study assessing genetic admixture in Latin-American populations estimated that the highest proportion of African ancestry occurs in Brazil (9.3\%) and Colombia (9.3\%). ${ }^{57}$ In fact, Brazil was the only other Latin American country whose allele distribution was comparable to our report. PON1 192R allele frequencies in other Latin-American countries, such as Argentina and Costa Rica, resemble Caucasian populations in agreement with the strong European ancestry of these countries. ${ }^{58}$ Our study provides new information on a no previously characterized population and emphasizes the importance of studying potential clinical biomarkers, such as PON1 Q192R amongst populations with different ethnic backgrounds. ${ }^{55}$ Importantly, high interindividual variability has been observed in PON1 activity due to environmental and genetic factors, including ethnic differences. ${ }^{59}$ In this context, it is increasingly necessary to conduct analyses assessing genetic risk factors in diverse populations. In agreement with this observation, Hernandez-Diaz et al found no association between the PON1 Q192R polymorphism and heart disease risk, nevertheless, in a stratified analysis by specific ethnicity, an association was found in Asian and African populations but not amongst Europeans or Americans. ${ }^{44}$ Future studies should consider this stratified approach.

Our case-control study involved an association test using allele frequencies from control public databases. Recent studies have highlighted the usefulness of public controls for genetic association studies. ${ }^{60,61}$ Existing genetic resources, such as the Genome Aggregation Database (gnomAD) (https://gnomad.broadinstitute.org/), enable this approach and may increase the power of association testing in a costeffective manner. ${ }^{31,61}$ From a public database containing 126,216 exomes and 15,137 genomes from unrelated individuals, we obtained ancestry-matched controls corresponding to 17,711 Latino/admixed American individuals. The importance of ethnically matched controls relies on the natural variability observed among human populations. Specifically, for PON1 Q192R we found that allelic frequencies can differ depending on ancestry (Table 3), and if ethnically diverse controls are used in case-control studies it is possible to find a false-positive association. ${ }^{62}$ Surprisingly, for the control population a HWE deviation was detected $(P$ $<0.05)$, a phenomenon not observed in the case-cohort $(P=$ 0.31). A previous report identified HWE deviation for this polymorphism produced by an excess of homozygotes. ${ }^{38}$ These observations can be explained by the Wahlund effect: a reduction in heterozygosity caused by subpopulation structure. We assume that this effect has no impact on our association results since if two or more subpopulations are in HWE but have different allele frequencies, the overall heterozygosity is reduced even if the subpopulations themselves are in HWE.

\section{Limitation of the Study}

First, our sample size represents only a fraction of Colombian patients with CAD and may influence statistical significance. Second, the PFA-200 assay had some limitations inherent to the test, for example, we could not quantify the exact values for samples that exceeded the detection limits (> 300 seconds). Third, even if the control population accounted for a large number of individuals, the database included a general Latin-American population and CAD cannot be discarded during the lifetime of the individuals. Furthermore, additional studies are required to exclude population-specific differences within Colombian population. Fourth, additional factors contributing to CAD development were unknown in the control population. Finally, despite using a curated public database to obtain 
genetic information from a large control population, it was not possible to match the case and control groups by age or gender because this information is not available at the individual level. Importantly, this database includes allele frequencies for controls-only subjects, with no cases from common disorders, including heart disease. While this information remains enormously useful for case-control and other studies, there are several challenges with using public databases as controls, including lack of individuallevel data and heterogeneity in data collection and processing.

\section{Conclusion}

Our study found that the PON1 Q192R polymorphism is associated with CAD susceptibility in the Colombian population and lacks association with HPR under clopidogrel treatment. To our knowledge, this is the first casecontrol association study between this polymorphism and cardiovascular disease risk in the Colombian population. Although more studies are required to translate these population-specific findings into the clinics, this report highlights the utility of genetic markers in pharmacogenetics and personalized medicine in the Latin-American population.

\section{Abbreviations}

ACS, acute coronary syndrome; AIC, Akaike's interpretation criterion; ADP, adenosine diphosphate; CABG, coronary artery bypass grafting; $\mathrm{CAD}$, coronary artery disease; CT; closure time; HDL, high-density lipoprotein; HPR, high on-treatment platelet reactivity; HWE, HardyWeinberg equilibrium; LDL, low-density lipoprotein; MAF, minor allele frequency; NSTEMI, non-ST-segment elevation myocardial infarction; PCI, percutaneous coronary intervention; PCR, polymerase chain reaction; PGE1, prostaglandin E1; PON1, Paraoxonase-1; SNP, single nucleotide polymorphism; STEMI, ST-segment elevation myocardial infarction.

\section{Data Sharing Statement}

Data obtained in our study are available from the corresponding authors on request.

\section{Ethical Considerations}

All procedures followed were in accordance with the ethical standards of the Universidad del Rosario's Ethics Committee (DVO005 990-CV1018; approval date: January 2019) and with the Helsinki Declaration of 1975, as revised in 2000. Informed consent was obtained from all patients for being included in the study.

\section{Acknowledgments}

The authors would like to thank the patients who participated in this study, the Hospital Universitario Mayor Méderi and Karen Panche who participated in patient recruitment and database organization for this study.

\section{Author Contributions}

All authors made substantial contributions to conception and design, acquisition of data, or analysis and interpretation of data; took part in drafting the article or revising it critically for important intellectual content; agreed to submit to the current journal; gave final approval for the version to be published; and agreed to be accountable for all aspects of the work.

\section{Funding}

This project was supported by Grants ABN062 and IVFPC015 (Universidad del Rosario) and Hospital Universitario Mayor - Méderi.

\section{Disclosure}

The funders had no role in study design, data collection or analysis, or preparation of the manuscript. The authors report no conflicts of interest in this work.

\section{References}

1. World Health Organization. Global Health Estimates: life expectancy and leading causes of death and disability. Global Health Estimates: life expectancy and leading causes of death and disability. 2019. Accessed June 9, 2021. https://www.who.int/data/gho/data/themes/mor tality-and-global-health-estimates.

2. Virani SS, Alonso A, Aparicio HJ, et al. Heart disease and stroke statistics - 2021 update. Circulation. 2021;143(8):155. doi:10.1161/ CIR.0000000000000950

3. Falk E, Nakano M, Bentzon JF, Finn AV, Virmani R. Update on acute coronary syndromes: the pathologists' view. Eur Heart J. 2013;34 (10):719-728. doi:10.1093/eurheartj/ehs411

4. Ponte-Negretti CI, Isea-Perez JE, Lorenzatti AJ, et al. Atherogenic Dyslipidemia in Latin America: prevalence, causes and treatment. Int J Cardiol. 2017;243:516-522. doi:10.1016/j.ijcard.2017.05.059

5. Lusis AJ, Mar R, Pajukanta P. Genetics of atherosclerosis. Annu Rev Genomics Hum Genet. 2004;5(1):189-218. doi:10.1146/annurev. genom.5.061903.175930

6. Arnett DK, Baird AE, Barkley RA, et al. Relevance of genetics and genomics for prevention and treatment of cardiovascular disease. Circulation. 2007;115(22):2878-2901. doi:10.1161/CIRCULATION AHA.107.183679

7. Mackness M, Mackness B. Human paraoxonase-1 (PON1): gene structure and expression, promiscuous activities and multiple physiological roles. Gene. 2015;567(1):12-21. doi:10.1016/j.gene.2015.04.088 
8. Shih DM, Xia YR, Wang XP, et al. Combined serum paraoxonase knockout/apolipoprotein E knockout mice exhibit increased lipoprotein oxidation and atherosclerosis. $J$ Biol Chem. 2000;275 (23):17527-17535. doi:10.1074/jbc.M910376199

9. Tward A, Xia Y-R, Wang X-P, et al. Decreased atherosclerotic lesion formation in human serum paraoxonase transgenic mice. Circulation. 2002;106(4):484-490. doi:10.1161/01.cir.0000023623.87083.4f

10. Zhao Y, Ma Y, Fang Y, et al. Association between PON1 activity and coronary heart disease risk: a meta-analysis based on 43 studies. $\mathrm{Mol}$ Genet Metab. 2012;105(1):141-148. doi:10.1016/j.ymgme.20 11.09 .018

11. Martínez-Quintana E, Rodríguez-González F, Medina-Gil JM, GaraySánchez P, Tugores A. Paraoxonase 1 (Q192R) gene polymorphism, coronary heart disease and the risk of a new acute coronary event. Clin Investig Arterioscler. 2017;29(1):1-6. doi:10.1016/j.arteri.20 16.07.005

12. Liu T, Zhang X, Zhang J, et al. Association between PON1 rs662 polymorphism and coronary artery disease. Eur J Clin Nutr. 2014;68 (9):1029-1035. doi:10.1038/ejen.2014.105

13. Imai $Y$, Morita $H$, Kurihara $H$, et al. Evidence for association between paraoxonase gene polymorphisms and atherosclerotic diseases. Atherosclerosis. 2000;149(2):435-442. doi:10.1016/s0021-9150(99) 00340-8

14. Gupta N, Singh S, Maturu VN, Sharma YP, Gill KD. Paraoxonase 1 (PON1) polymorphisms, haplotypes and activity in predicting cad risk in North-West Indian Punjabis. PLoS One. 2011;6(5):e17805. doi:10.1371/journal.pone. 0017805

15. Hassan MA, Al-Attas OS, Hussain T, et al. The Q192R polymorphism of the paraoxonase 1 gene is a risk factor for coronary artery disease in Saudi subjects. Mol Cell Biochem. 2013;380(1-2):121128. doi:10.1007/s11010-013-1665-z

16. Bounafaa A, Berrougui H, Ghalim N, et al. Association between Paraoxonase 1 (PON1) Polymorphisms and the Risk of Acute Coronary Syndrome in a North African Population. PLoS One. 2015;10(8):e0133719. doi:10.1371/journal.pone.0133719

17. Luu HN, Kingah PL, North K, Boerwinkle E, Volcik KA. Interaction of folate intake and the paraoxonase Q192R polymorphism with risk of incident coronary heart disease and ischemic stroke: the atherosclerosis risk in communities study. Ann Epidemiol. 2011;21 (11):815-823. doi:10.1016/j.annepidem.2011.08.007

18. Moreno-Godínez ME, Galarce-Sosa C, Cahua-Pablo JÁ, et al. Genotypes of Common Polymorphisms in the PON1 Gene Associated with Paraoxonase Activity as Cardiovascular Risk Factor. Arch Med Res. 2018;49(7):486-496. doi:10.1016/j. arcmed.2019.02.002

19. de Souza-nogueira A, Camargo AE, Remondi FA, et al. Paraoxonase 1 (PON1) Q192R genotypes and their interaction with smoking strongly increase atherogenicity and the Framingham risk score. Arch Endocrinol Metab. 2016;60(5):426-435. doi:10.1590/23593997000000184

20. Gardemann A, Philipp M, Hess K, Katz N, Tillmanns H, Haberbosch W. The paraoxonase Leu-Met54 and Gln-Arg191 gene polymorphisms are not associated with the risk of coronary heart disease. Atherosclerosis. 2000;152(2):421-431. doi:10.1016/s0021-9150(99) 00489-x

21. Ombres D, Pannitteri G, Montali A, et al. The gln-Arg192 polymorphism of human paraoxonase gene is not associated with coronary artery disease in Italian patients. Arterioscler Thromb Vasc Biol. 1998;18(10):1611-1616. doi:10.1161/01.atv.18.10.1611

22. Antikainen M, Murtomäki S, Syvänne M, et al. The Gln-Arg191 polymorphism of the human paraoxonase gene (HUMPONA) is not associated with the risk of coronary artery disease in Finns. $J$ Clin Invest. 1996;98(4):883-885. doi:10.1172/JCI118869

23. Bouman HJ, Schömig E, van Werkum JW, et al. Paraoxonase-1 is a major determinant of clopidogrel efficacy. Nat Med. 2011;17(1):110116. doi: $10.1038 / \mathrm{nm} .2281$
24. Rodriguez F, Mahaffey KW. Management of Patients With NSTEACS: a Comparison of the Recent AHA/ACC and ESC Guidelines. $J$ Am Coll Cardiol. 2016;68(3):313-321. doi:10.1016/j. jacc.2016.03.599

25. Peng W, Shi X, Xu X, Lin Y. Both CYP2C19 and PON1 Q192R genotypes influence platelet response to clopidogrel by thrombelastography in patients with acute coronary syndrome. Cardiovasc Ther. 2019;2019:3470145. doi:10.1155/2019/3470145

26. Serebruany VL, Steinhubl SR, Berger PB, Malinin AI, Bhatt DL, Topol EJ. Variability in platelet responsiveness to clopidogrel among 544 individuals. $J$ Am Coll Cardiol. 2005;45(2):246-251. doi:10.1016/j.jacc.2004.09.067

27. Shuldiner AR, O'Connell JR, Bliden KP, et al. Association of cytochrome $\mathrm{P} 4502 \mathrm{C} 19$ genotype with the antiplatelet effect and clinical efficacy of clopidogrel therapy. JAMA. 2009;302(8):849-857. doi:10.1001/jama.2009.1232

28. Sugunaraj JP, Palaniswamy C, Selvaraj DR, Chaitanya Arudra SK, Sukhija R. Clopidogrel resistance. Am J Ther. 2010;17(2):210-215. doi:10.1097/MJT.0b013e3181bdc3e4

29. Angulo-Aguado M, Panche K, Tamayo-Agudelo CA, et al. A Pharmacogenetic Study of CYP2C19 in Acute Coronary Syndrome Patients of Colombian Origin Reveals New Polymorphisms Potentially Related to Clopidogrel Therapy. Journal of Personalized Medicine. 2021;11(5):400. doi:10.3390/jpm11050400

30. Senior J, Lugo L, Acosta N, et al. Guía de práctica clínica para pacientes con diagnóstico de síndrome coronario agudo; atención inicial y revascularización. Revista Colombiana De Cardiologia. 2013;20:45-85.

31. Karczewski KJ, Francioli LC, Tiao G, et al. The mutational constraint spectrum quantified from variation in 141,456 humans. Nature. 2020;581(7809):434-443. doi:10.1038/s41586-020-2308-7

32. González JR, Armengol L, Solé X, et al. SNPassoc: an R package to perform whole genome association studies. Bioinformatics. 2007;23 (5):644-645. doi:10.1093/bioinformatics/btm025

33. Regieli JJ, Jukema JW, Doevendans PA, et al. Paraoxonase variants relate to 10-year risk in coronary artery disease: impact of a high-density lipoprotein-bound antioxidant in secondary prevention. $J$ Am Coll Cardiol. 2009;54(14):1238-1245. doi:10.1016/j.jacc.2009.05.061

34. Marija G, Karmela B, Lada R, et al. Genetic Frequencies of Paraoxonase 1 Gene Polymorphisms in Croatian Population. Croatica Chemica Acta. 2008;81(1):101-105.

35. Scacchi R, Corbo RM, Rickards O, De Stefano GF. New data on the world distribution of paraoxonase (PON1 Gln $192 \rightarrow$ Arg) gene frequencies. Hum Biol. 2003;75(3):365-373. doi:10.1353/hub.2003.0049

36. Helaly MA-H, Abdel-Khalek EE-S, Abdel-Hafez HA, Soliman AW, Daoud EM, Lotfy ZF. Paraoxonase1 55 and 192 gene polymorphisms in an Egyptian population with diabetic complications. Int J Diabetes Dev Ctries. 2013;33(4):207-212. doi:10.1007/s13410-013-0146-y

37. Carranza Alva E, Peña Suasnábar C, Carranza Florenti A. Distribution of the Q192R polymorphism of the paraoxonase 1 gene in a population of the district of Junín (Junín region, Peru). HorizMed. 2017;17(2):22-29. doi:10.24265/horizmed.2017.v17n2.04

38. Fridman O, Gariglio L, Riviere S, Porcile R, Fuchs A, Potenzoni M. Paraoxonase 1 gene polymorphisms and enzyme activities in coronary artery disease and its relationship to serum lipids and glycemia. Arch Cardiol Mex. 2016;86(4):350-357. doi:10.1016/j.acmx.20 16.08 .001

39. Sen-Banerjee S, Siles X, Campos H. Tobacco Smoking Modifies Association Between Gln-Arg192 Polymorphism of Human Paraoxonase Gene and Risk of Myocardial Infarction. Arterioscler Thromb Vasc Biol. 2000;20(9):2120-2126. doi:10.1161/01. ATV.20.9.2120

40. Orengo-Mercado C. Frequencies of Functional Polymorphisms in Three Pharmacokinetic Genes of Clinical Interest within the Admixed Puerto Rican Population. $J$ Pharmacogenom Pharmacoproteomics. 2013;04:01. doi:10.4172/2153-0645.1000113 
41. Siller-López F, Garzón-Castaño S, Ramos-Márquez ME, HernándezCañaveral I. Association of Paraoxonase-1 Q192R (rs662) Single Nucleotide Variation with Cardiovascular Risk in Coffee Harvesters of Central Colombia. J Toxicol. 2017;2017:6913106. doi:10.1155/ 2017/6913106

42. Karlsson H, Kontush A, James RW. Functionality of HDL: antioxidation and detoxifying effects. Handb Exp Pharmacol. 2015;224:207-228. doi:10.1007/978-3-319-09665-0_5

43. Shih DM, Gu L, Xia Y-R, et al. Mice lacking serum paraoxonase are susceptible to organophosphate toxicity and atherosclerosis. Nature. 1998;394(6690):284-287. doi:10.1038/28406

44. Hernández-Díaz Y, Tovilla-Zárate CA, Juárez-Rojop IE, et al. Effects of paraoxonase 1 gene polymorphisms on heart diseases: systematic review and meta-analysis of 64 case-control studies. Medicine. 2016;95(44):e5298. doi:10.1097/MD.0000000000005298

45. Bhattacharyya T, Nicholls SJ, Topol EJ, et al. Relationship of paraoxonase 1 (PON1) gene polymorphisms and functional activity with systemic oxidative stress and cardiovascular risk. JAMA. 2008;299 (11):1265-1276. doi:10.1001/jama.299.11.1265

46. Ferré N, Tous M, Paul A, et al. Paraoxonase Gln-Arg(192) and LeuMet(55) gene polymorphisms and enzyme activity in a population with a low rate of coronary heart disease. Clin Biochem. 2002;35 (3):197-203. doi:10.1016/S0009-9120(02)00295-3

47. Hampe M, Mogarekar M. Paraoxonase1, its Q192R polymorphism and HDL-cholesterol in relation to intensive cardiac care unit stay in ischemic heart disease. Indian J Hum Genet. 2014;20(1):51. doi:10.4103/0971-6866.132756

48. Bayrak A, Bayrak T, Tokgözoglu SL, et al. Serum PON-1 Activity but not Q192R Polymorphism is Related to the Extent of Atherosclerosis. JAT. 2012;19(4):376-384. doi:10.5551/jat.11320

49. Munshi R, Panchal F, Chaurasia A, Rajadhyaksha G. Association between Paraoxonase 1(PON1) Gene Polymorphisms and PON1 Enzyme Activity in Indian Patients with Coronary Artery Disease (CAD). CPPM. 2019;16(3):219-229. doi:10.2174/187569211766 6181227112119

50. Costa LG, Cole TB, Jarvik GP, Furlong CE. Functional Genomics of the Paraoxonase (PON1) Polymorphisms: effects on Pesticide Sensitivity, Cardiovascular Disease, and Drug Metabolism. Annu Rev Med. 2003;54 (1):371-392. doi:10.1146/annurev.med.54.101601.152421

51. Lewis JP, Fisch AS, Ryan K, et al. Paraoxonase 1 (PON1) gene variants are not associated with clopidogrel response. Clin Pharmacol Ther. 2011;90(4):568-574. doi:10.1038/clpt.2011.194
52. Hulot J-S, Collet J-P, Cayla G, et al. CYP2C19 but not PON1 genetic variants influence clopidogrel pharmacokinetics, pharmacodynamics, and clinical efficacy in post-myocardial infarction patients. Circ Cardiovasc Interv. 2011;4(5):422-428. doi:10.1161/CIRCINTER VENTIONS.111.963025

53. Camps J, Joven J, Mackness B, et al. Paraoxonase-1 and clopidogrel efficacy. Nat Med. 2011;17(9):1041-1042. doi:10.1038/nm.2386

54. Garcia A. Paraoxonase-1 Deficiency does not Influence Clopidogrel Antiplatelet Function in Mice. Cardiovasc Pharmacol. 2015;4:3. doi:10.4172/2329-6607.1000148

55. Ginsberg G, Neafsey P, Hattis D, Guyton KZ, Johns DO, Sonawane B. Genetic polymorphism in paraoxonase 1 (PON1): population distribution of PON1 activity. J Toxicol Environ Health B Crit Rev. 2009;12(5-6):473-507. doi:10.1080/10937400903158409

56. Salzano FM, Sans M. Interethnic admixture and the evolution of Latin American populations. Genet Mol Biol. 2014;37(1 Suppl):151-170. doi:10.1590/s1415-47572014000200003

57. Adhikari K, Mendoza-Revilla J, Chacón-Duque JC, FuentesGuajardo M, Ruiz-Linares A. Admixture in Latin America. Curr Opin Genet Dev. 2016;41:106-114. doi:10.1016/j.gde.2016.09.003

58. Avena S, Via M, Ziv E, et al. Heterogeneity in genetic admixture across different regions of Argentina. PLoS One. 2012;7(4):e34695. doi:10.1371/journal.pone.0034695

59. Roest M, van Himbergen TM, Barendrecht AB, Peeters PHM, van der Schouw YT, Voorbij HAM. Genetic and environmental determinants of the PON-1 phenotype. Eur J Clin Invest. 2007;37(3):187196. doi:10.1111/j.1365-2362.2007.01769.x

60. Hendricks AE, Billups SC, Pike HNC, et al. ProxECAT: proxy External Controls Association Test. A new case-control gene region association test using allele frequencies from public controls. PLoS Genet. 2018;14(10):e1007591. doi:10.1371/journal.pgen.1007591

61. Li Y, Lee S. Novel score test to increase power in association test by integrating external controls. Genet Epidemiol. 2021;45(3):293-304. doi:10.1002/gepi.22370

62. Ghouse J, Skov MW, Bigseth RS, Ahlberg G, Kanters JK, Olesen MS. Distinguishing pathogenic mutations from background genetic noise in cardiology: the use of large genome databases for genetic interpretation. Clin Genet. 2018;93(3):459-466. doi:10.1111/ cge. 13066
Vascular Health and Risk Management

\section{Publish your work in this journal}

Vascular Health and Risk Management is an international, peerreviewed journal of therapeutics and risk management, focusing on concise rapid reporting of clinical studies on the processes involved in the maintenance of vascular health; the monitoring, prevention and treatment of vascular disease and its sequelae; and the involvement of metabolic disorders, particularly diabetes. This journal is indexed on PubMed Central and MedLine. The manuscript management system is completely online and includes a very quick and fair peerreview system, which is all easy to use. Visit http://www.dovepress. com/testimonials.php to read real quotes from published authors. 